\section{An interactive, self-instructing FORTRAN program for one- and two-way analyses of variance}

\section{ARTHUR J. FLEXSER \\ Florida International University, Miami, Florida 33199}

The FORTRAN program described here was designed to permit the user to interactively perform one-and twoway analyses of variance for within-subjects, betweensubjects, and mixed designs. A primary objective in the design of the program was to achieve the utmost simplicity of usage: It was desired that a first-time user of the program, even a complete computer novice, should be able to correctly perform an analysis of variance without the necessity for any instructions other than those printed out by the program. Thus, all requests for user input are made very explicit and output is made clear and concise.

The motivation for designing a program with these goals in mind was primarily instructional: I wanted to give our psychology laboratory students the capability of routinely performing analyses of variance interactively using the university computer, but I did not wish to have to devote any appreciable class time to explaining the idiosyncrasies and complexities of widely available programs such as those included in the BMDP, SPSS, and other similar series. The program has now been used instructionally at Florida International University (FIU) for several years, with introductory undergraduate laboratory students achieving a high degree of accuracy with virtually no need for instructor assistance. In spite of the program's having been designed primarily with instructional uses in mind, it has been found to be sufficiently powerful and convenient that it has become a frequently used data analysis tool for research in the psychology department at FIU.

The program assumes a fixed-effects model with equal sample sizes. Computational procedures are based on those given in Myers (1979).

Input. The program initially prompts the user for a design code $(1,2$, or 3$)$, depending on whether a between-subjects, within-subjects, or mixed design is being analyzed. The program then requests a name (up to six characters) for the first independent variable. The number of levels of this variable and a name for each level are then requested. Similar prompts are given for the second independent variable; a carriage retum in place of the name of this variable tells the program that a one-way analysis of variance is desired. In the case of a mixed design, the program instructs the user that the within-subjects variable must be entered first

Data are then entered cell by cell in free format, with each cell being prompted for by name (e.g., DELAY = 1 MIN, RATE = SLOW). The program has no facilities for correction of erroneous data entries, but this lack proves not to be a serious problem since one rapidly gets into the habit of proofreading each line of data before pressing carriage return, enabling corrections to be made using the RUBOUT or DELETE Teletype keys.

Output. The program's standard output is confined to the information that would normally appear in a psychology journal article, and this information is supplied in a pseudo-APA-style format. Thus, rather than routinely printing the entire ANOVA summary table, the program supplies only the relevant $F$ values, degrees of freedom, and mean squares for error for main effects and interaction [e.g., MAIN EFFECT OF DELAY: $\mathrm{F}(3,72)=12.31$, MEAN SQUARE FOR ERROR = $1.368]$. Following this information is printed a table of cell means and marginals, employing the user-supplied labels for variables and levels. Finally, the user is given the option of having the summary table printed out if desired.

Limitations. The number of levels permitted for each independent variable and the maximum number of observations permitted per cell are controlled by array dimensioning. Instructions for modifying these limits are included as comments in the source program.

Language. The program is written in FORTRAN IV and has been compiled successfully both on an IBM 370 computer using WATFIV and on a UNIVAC $1100 \mathrm{com}$ puter using ASCII FORTRAN. Machine-specific FORTRAN features have been avoided. The program, including comments, consists of 322 lines of source code.

Availability. A program listing is available free of charge from Arthur J. Flexser, Department of Psychology, Florida International University, Tamiami Campus, Miami, Florida 33199. A companion program, written in the same spirit, for performing $t$ tests (paired or independent observations) is also available on request. Soft-copy versions of either or both programs may be obtained at a cost of $\$ 5$ to cover expenses by sending a standard magnetic tape to the author.

\section{REFERENCE}

Myers, J. L. Fundamentals of experimental design (3rd ed.). Boston: Allyn \& Bacon, 1979.

(Accepted for publication March 15, 1982.) 